\title{
Article \\ Multi-Systemic Alterations by Chronic Exposure to a Low Dose of Bisphenol A in Drinking Water: Effects on Inflammation and $\mathrm{NAD}^{+}$-Dependent Deacetylase Sirtuin1 in Lactating and Weaned Rats
}

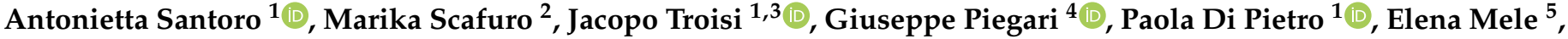 \\ Donato Cappetta ${ }^{6}$, Marianna Marino ${ }^{1}$ (D), Antonella De Angelis ${ }^{6}$, Carmine Vecchione ${ }^{1,7}$, Orlando Paciello ${ }^{4}$, \\ Silvia Fasano ${ }^{6}$, Riccardo Pierantoni ${ }^{6}$, Andrea Viggiano ${ }^{1,+}$ and Rosaria Meccariello ${ }^{5, *}++^{+}$
}

check for updates

Citation: Santoro, A.; Scafuro, M.;

Troisi, J.; Piegari, G.; Di Pietro, P.;

Mele, E.; Cappetta, D.; Marino, M.; De Angelis, A.; Vecchione, C.; et al. Multi-Systemic Alterations by Chronic Exposure to a Low Dose of Bisphenol A in Drinking Water: Effects on Inflammation and $\mathrm{NAD}^{+}$-Dependent Deacetylase Sirtuin1 in Lactating and Weaned Rats. Int. J. Mol. Sci. 2021, 22, 9666. https://doi.org/10.3390/ijms22189666

Academic Editor: Eui-Bae Jeung

Received: 8 August 2021

Accepted: 1 September 2021

Published: 7 September 2021

Publisher's Note: MDPI stays neutral with regard to jurisdictional claims in published maps and institutional affiliations.

Copyright: (c) 2021 by the authors. Licensee MDPI, Basel, Switzerland. This article is an open access article distributed under the terms and conditions of the Creative Commons Attribution (CC BY) license (https:/ / creativecommons.org/licenses/by/ $4.0 /)$.
1 Department of Medicine, Surgery and Dentistry "Scuola Medica Salernitana”, University of Salerno, 84081 Baronissi, Italy; ansantoro@unisa.it (A.S.); troisi@theoreosrl.com (J.T.); pdipietro@unisa.it (P.D.P.); mamarino@unisa.it (M.M.); cvecchione@unisa.it (C.V.); aviggiano@unisa.it (A.V.)

2 Department of Precision Medicine, University of Campania "Luigi Vanvitelli", 80138 Naples, Italy; marika.scafuro@unicampania.it

3 Theoreo srl Spinoff Company of the University of Salerno European Biomedical, 84090 Montecorvino Pugliano, Italy

4 Unit of Pathology, Department of Veterinary Medicine and Animal Production, University of Naples Federico II, 80137 Naples, Italy; giuseppe.piegari@unina.it (G.P.); paciello@unina.it (O.P.)

5 Department of Movement Sciences and Wellbeing, Parthenope University of Naples, 80133 Naples, Italy; elena.mele@collaboratore.uniparthenope.it

6 Department of Experimental Medicine, University of Campania “Luigi Vanvitelli", 80138 Naples, Italy; donato.cappetta@unicampania.it (D.C.); antonella.deangelis@unicampania.it (A.D.A.); silvia.fasano@unicampania.it (S.F.); riccardo.pierantoni@unicampania.it (R.P.)

7 IRCCS Neuromed, Department of Vascular Physiopathology, 86077 Pozzilli, Italy

* Correspondence: rosaria.meccariello@uniparthenope.it; Tel.: +39-081-5744668

+ These authors equally contributed to the work.

Abstract: Bisphenol A (BPA) is largely used as a monomer in some types of plastics. It accumulates in tissues and fluids and is able to bypass the placental barrier, affecting various organs and systems. Due to huge developmental processes, children, foetuses, and neonates could be more sensitive to BPA-induced toxicity. To investigate the multi-systemic effects of chronic exposure to a low BPA dose $(100 \mu \mathrm{g} / \mathrm{L})$, pregnant Wistar rats were exposed to BPA in drinking water during gestation and lactation. At weaning, newborn rats received the same treatments as dams until sex maturation. Free and conjugated BPA levels were measured in plasma and adipose tissue; the size of cerebral ventricles was analysed in the brain; morpho-functional and molecular analyses were carried out in the liver with a focus on the expression of inflammatory cytokines and Sirtuin 1 (Sirt1). Higher BPA levels were found in plasma and adipose tissue from BPA treated pups (17 PND) but not in weaned animals. Lateral cerebral ventricles were significantly enlarged in lactating and weaned BPA-exposed animals. In addition, apart from microvesicular steatosis, liver morphology did not exhibit any statistically significant difference for morphological signs of inflammation, hypertrophy, or macrovesicular steatosis, but the expression of inflammatory cytokines, Sirt1, its natural antisense long non-coding RNA (Sirt1-AS LncRNA) and histone deacetylase 1 (Hdac1) were affected in exposed animals. In conclusion, chronic exposure to a low BPA dose could increase the risk for disease in adult life as a consequence of higher BPA circulating levels and accumulation in adipose tissue during the neonatal period.

Keywords: BPA; liver; cerebral ventricles; Sirt1; Sirt1-AS LncRNA; epigenetics; inflammation 


\section{Introduction}

Bisphenol A [BPA,2,2-bis (4-hydroxyphenyl) propane] is one of the most common environmental pollutants routinely used to produce epoxy resins and polycarbonate plastics [1,2]. Acidic/basic food and drinks, high temperature or biological fluids cause BPA leaching in the environment and humans are commonly exposed through skin contact, inhalation, or ingestion of contaminated foods and beverages [3]. BPA can interfere with the endocrine system through mechanisms involving the link to steroid receptors like the nuclear estrogen receptor (ER) (i.e., ER $\alpha$ and ER $\beta$ ), the membrane estrogen receptor GPER30, the estrogen-related receptor $\gamma(\mathrm{ERR} \gamma)$, or androgen receptor (AR), thus exhibiting estrogenic and anti-androgenic activities [4]. Therefore, BPA causes reproductive, developmental, inflammatory, and metabolic dysfunctions in humans and animal models [2,3,5-10].

When ingested, BPA's fate and disposition in the body first depend on the ability of the gastrointestinal tract and liver to metabolise the compound to a hydrophilic form with low estrogenic activity. Glucuronidation by UDP-glucuronosyltransferases (UGTs) is the main pathway of BPA metabolic detoxification in both the intestine and liver [11]. In the proximal intestine, the transformation of unconjugated BPA (free BPA) into conjugated BPA (BPA-G) limits the adsorption of free BPA, thus representing a barrier that prevents BPA toxic effects. In the liver, free BPA is thought to be rapidly glucuronidated in the hepatic microsomes to be excreted through bile or urine as BPA-G. However, tissues like the intestine, liver, kidney, or placenta express the enzyme $\beta$-glucuronidase that can deconjugate BPA and thus release its active form again [11]. Consequently, BPA bio-accumulates in biological tissues and fluids like white adipose tissue [12] and maternal milk [13,14] and bypasses the placental barrier, thus reaching the foetus [15-17]. In animal models and humans, the BPA-dependent outcomes on health depend on life stage, doses, exposure route or time as well, but gestational, neonatal and perinatal timeframes are more sensitive to BPA exposure due to massive developmental processes [1] and the limited ability of the liver to conjugate BPA with respect to adult life [11]. Nevertheless, while oxidative stress and tissue damages have been considered for a long time as the main consequences of BPA exposure, recently, epigenetic effects-including the transgenerational ones-leading to behavioural, reproductive, and metabolic disorders have been documented [3,5].

In the brain, BPA interferes with the central control of reproduction [5] and also in energy homeostasis, appetite regulation [18,19], and immune surveillance functions [20], with activity on the hypothalamic reproductive neurohormones, orexigenic/anorexigenic neuropeptides, microglia, and astrocytes $[5,9,10,20]$. Apart from the effects on gamete quality, reproduction, and fertility [3,5], at the periphery, BPA targets both liver and white adipose tissue causing the deregulation of glucose and lipid metabolism and affects adipogenesis [9]. Thus, the main consequence of BPA exposure in the liver is the occurrence of oxidative stress, impaired mitochondrial functions, and increased lipid storage, ultimately leading to liver steatosis [9,21-24]. Epigenetic reprogramming of genes involved in lipid metabolism has been demonstrated in the liver of long-term exposed mice [25]. In this respect, BPA could act as an obesogenic compound, raising the risk of overweight and obesity in both exposed subjects and their offspring through trans-generational epigenetic mechanisms $[19,26]$.

Interestingly, the Sirtuin 1 (Sirt1), the nuclear $\mathrm{NAD}^{+}$-dependent class III deacetylase, is an epigenetic target of environmental exposure to toxicants [27], being directly involved in coupling the cellular metabolic status (via NAD ${ }^{+}$) to the modulation of both chromatin structure and gene expression with mechanisms involving the deacetylation of histone proteins or non-histone proteins like transcription factors, co-factors, or nuclear receptors (i.e., FOXO-1, p53, Nf-kb, PGC1- $\alpha$, AR, ER $\alpha$, LXRa, etc.) [28,29]. Sirt1, also known as the "longevity gene", protects cells against apoptosis and inflammation and is involved in the control of cell proliferation, differentiation, or death and has gained considerable attention in epigenetic mechanisms [30]. Changes in Sirt1 expression are critical in several diseases, such as cardiovascular diseases, metabolic syndrome, cancer, neurodegeneration, and 
infertility [29,31-35]. In the liver, Sirt1 is involved in the control of both glucose and lipid metabolism [36,37] with different downstream pathways, including histone modification in the nucleus or p53 dependent apoptotic pathways aimed at counteracting the accumulation of hepatic oxidative stress and inflammation [37].

Since BPA exposure may represent a health risk, in this manuscript, we analysed the multi-systemic alterations in rat tissues induced by chronic exposure to a low dose of BPA. In order to mimic one of the main exposure routes in humans, BPA was administered in drinking water first to dams during pregnancy and lactation and then, at weaning, also to the newborns. Hence, free BPA and BPA-G were measured in plasma, and BPA accumulation was measured in white adipose tissue. Then, morpho-functional evaluations were carried out in the brain and liver because they are well-known targets of BPA activity. In parallel, the expression profile of molecular markers of inflammation (i.e., inflammatory cytokines and the inflammation related transcriptional factor Nf-kb) and Sirt1 protein were compared in the livers of lactating and weaned animals. To provide further insights into the possible epigenetic targets of BPA, Sirt1 mRNA, its natural antisense long non-coding RNA (Sirt1-AS LncRNA), and the expression rate of the main DNA methylation and deacetylating enzymes were also analysed in the livers of weaned animals.

\section{Results}

\subsection{Experimental Groups and Body Weight}

The experimental groups were composed as described in Table 1, the mean body weight did not differ between control and BPA treated animals at all ages and in both sexes.

Table 1. Experimental groups and body weight.

\begin{tabular}{cccccc}
\hline & & \multicolumn{2}{c}{$\boldsymbol{n}$. of Subjects } & \multicolumn{2}{c}{$\begin{array}{c}\text { Weight (g) } \\
\text { Mean } \pm \text { SE }\end{array}$} \\
\hline \multirow{2}{*}{ Lactating } & Treatment & Males & Females & Males & Females \\
\cline { 2 - 6 } & Control & 6 & 5 & $34 \pm 4$ & $35 \pm 4$ \\
\cline { 2 - 6 } Weaned & BPA & 7 & 6 & $29 \pm 4$ & $27 \pm 4$ \\
\cline { 2 - 6 } & Control & 9 & 7 & $220 \pm 14$ & $155 \pm 10$ \\
\hline & BPA & 10 & 9 & $232 \pm 11$ & $150 \pm 12$ \\
\hline
\end{tabular}

\subsection{BPA Concentration in Plasma and Adipose Tissue}

BPA exposure produced an increased concentration of free-plasma-BPA (Figure 1A), plasma-BPA-G (Figure 1B), and adipose-tissue-BPA (Figure 1C) in lactating but not in young rats.

The ANOVA for free-plasma-BPA showed a significant effect for the treatment $(\mathrm{F} 1,24=5.49$, $p<0.05)$, for time ( $\mathrm{F} 1,24=4.7, p<0.05)$, and for the treatment $\mathrm{x}$ time interaction $(\mathrm{F} 1,24=8.23$, $p<0.01)$. The Tukey's post hoc test demonstrated that the BPA-treated group at 10-17 PND was statistically different from the others $(p<0.05)$.

The ANOVA for BPA in adipose tissue showed a significant effect dependent on the treatment $(\mathrm{F} 1,24=4.41, p<0.05)$, the time $(\mathrm{F} 1,24=6.44, p<0.05)$, and the treatment $\mathrm{x}$ time interaction (F1,24 $=6.96, p<0.05)$. The Tukey's post hoc test demonstrated that the BPA-treated group at 10-17 PND was different from the others $(p<0.05)$. 
A

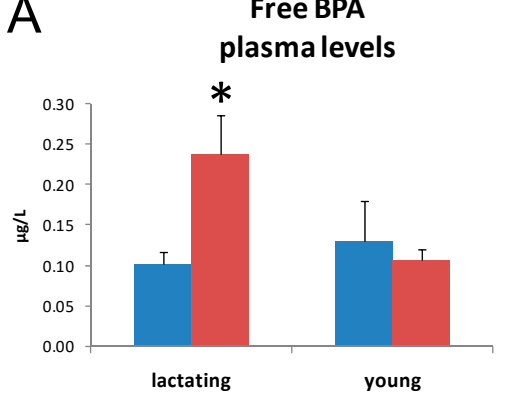

\section{C}

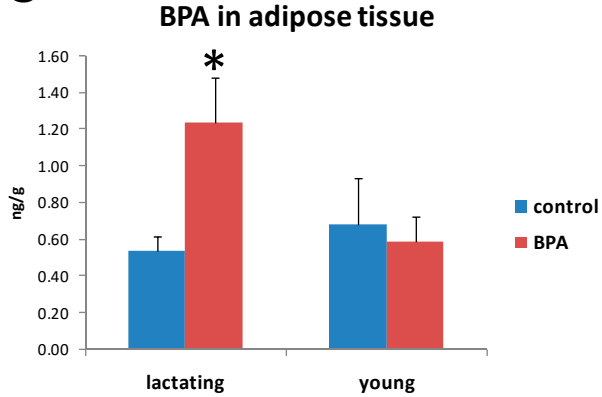

B
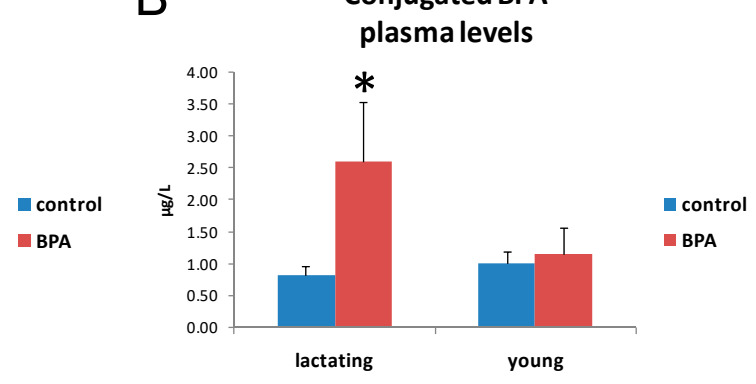

Figure 1. Free-BPA plasma levels in lactating and young rats drinking BPA-added (BPA) or tap water (control) (A). Conjugated-BPA plasma levels in lactating and young rats drinking BPA-added (BPA) or tap water (control) (B). BPA levels in adipose tissue from lactating and young rats drinking BPA-added (BPA) or tap water (control) (C). Data are reported as mean and SE. ${ }^{*} p<0.05$ compared to all other groups.

\subsection{Nissl Staining and Measurement of Ventricle Size}

To assess the effects of BPA exposure in brain structures known to be important for the maintenance of neurons and glial homeostasis, we analysed lateral ventricles morphology and size on lactating and weaned rats (Figure 2A). Quantification of the total ventricular area revealed significant enlargement of the lateral ventricles in the brains of lactating and weaned rats chronically exposed to BPA ( $p<0.05$ vs. control group) (Figure 2B).

A
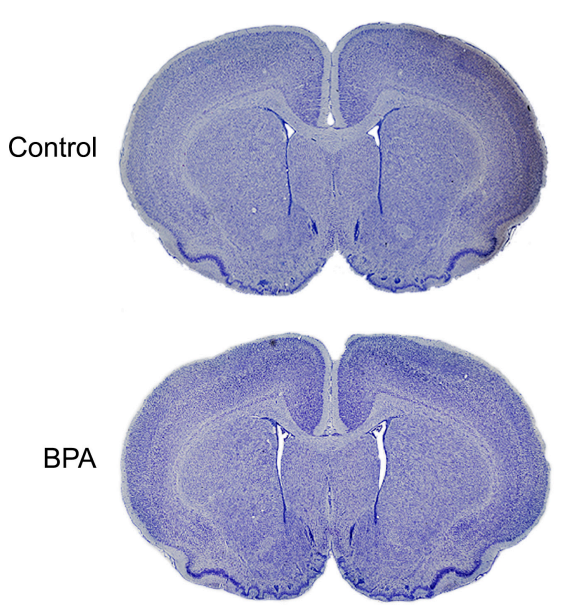

B

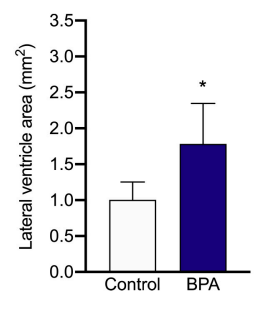

C

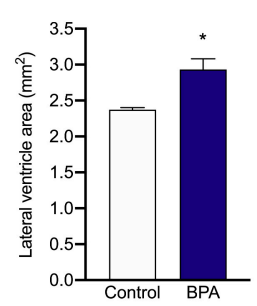

Figure 2. (A), Representative brain Nissl-stained sections of rats from PND 17 BPA-treated and control dams. (B,C), Bar graphs showing the lateral ventricular size measured by cross-sectional area of the brains in (B), PND 17 and (C), PND 60 rats from vehicle- and BPA-treated dams. Data are expressed as mean $\pm \mathrm{SE}, n=5$ per group, ${ }^{*} p<0.05$. 


\subsection{Histological Analysis of the Liver}

The main histological alteration of the liver was a mild to moderate microvesicular steatosis in all groups except in the control lactating group (Figure 3, Table 2). The KruskalWallis test showed a significant difference for the microvesicular steatosis between the groups $(K=9.25, p<0.05)$. Pairing comparison with the Mann-Whitney $U$ test showed that the lactating control group was different from the others (Table 2). Mild hepatocellular hypertrophy was observed in some BPA exposed lactating or weaned animals. After grouping data from lactating and weaning rats, the Mann-Whitney $U$ test showed a significant difference between the BPA-treated and the control groups.

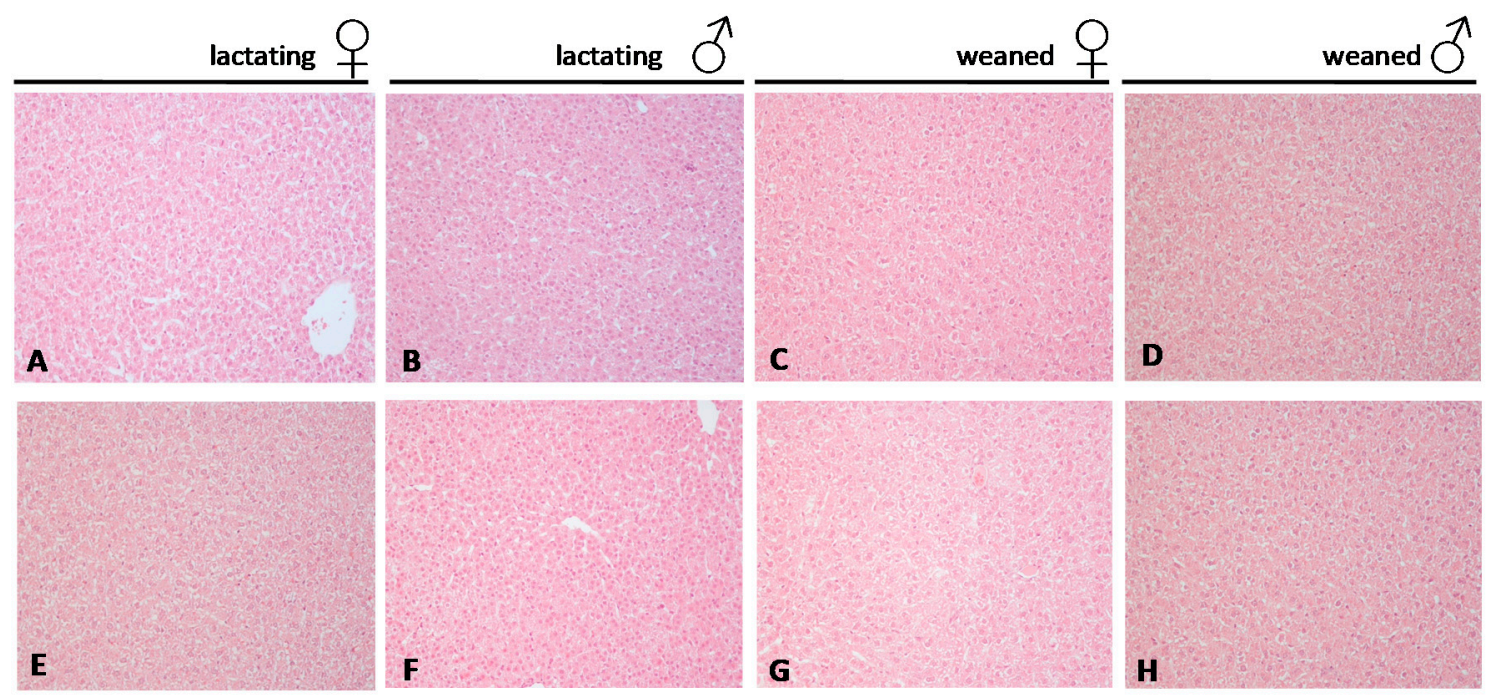

Figure 3. Representative haematoxylin and eosin-stained sections from liver tissue of rats. (A-D) controls, (E-H) BPA treated. (original magnification $20 \times$ ). Females $\uparrow$, males $\sigma^{x}$.

Table 2. Histological features of liver from control and BPA-treated rats at 10-17 PND and 45-60 PND.

\begin{tabular}{|c|c|c|c|c|c|}
\hline & & $\begin{array}{c}\text { Macrovesicular } \\
\text { Steatosis }\end{array}$ & $\begin{array}{c}\text { Microvesicular } \\
\text { Steatosis }\end{array}$ & Hypertrophy & Inflammation \\
\hline \multirow[t]{2}{*}{ Lactating } & Control & $0.09 \pm 0.10$ & $\begin{array}{c}* 0.45 \pm 0.22 \\
(p<0.05)\end{array}$ & $0.00 \pm 0.00$ & $0.18 \pm 0.13$ \\
\hline & BPA & $0.00 \pm 0.00$ & $1.47 \pm 0.26$ & $0.33 \pm 0.13$ & $0.13 \pm 0.09$ \\
\hline \multirow{2}{*}{ Young } & Control & $0.00 \pm 0.00$ & $1.00 \pm 0.35$ & $0.00 \pm 0.00$ & $0.33 \pm 0.18$ \\
\hline & BPA & $0.00 \pm 0.00$ & $1.53 \pm 0.23$ & $0.26 \pm 0.11$ & $0.00 \pm 0.00$ \\
\hline
\end{tabular}

Data are expressed as mean \pm SE. * Statistically significant difference vs. control group.

\subsection{Molecular Markers in Liver}

\subsubsection{Inflammation}

The expression rate of Tnf $\alpha, I l-6$, and $N f-k b$ was analysed by qPCR in lactating and young animals by qPCR (Table 3 ). The expression rate of all the selected biomarkers resulted to be significantly higher in lactating BPA exposed animals ( $p<0.05$ vs. control group). Tnfa and $N f-k b$ mRNA remained higher in weaned BPA exposed animals, with weaker effects in lactating animals. Il-6 mRNA levels did not change in weaned animals. 
Table 3. Expression analysis of inflammation biomarkers in lactating (17 PND) and weaned (60 PND) animals.

\begin{tabular}{|c|c|c|c|c|}
\hline \multirow[b]{2}{*}{ mRNA } & \multicolumn{2}{|c|}{17 PND } & \multicolumn{2}{|c|}{60 PND } \\
\hline & $\begin{array}{l}\text { Control } \\
(n=4-6)\end{array}$ & $\begin{array}{c}\text { BPA } \\
(n=4-6)\end{array}$ & $\begin{array}{l}\text { Control } \\
(n=4-6)\end{array}$ & $\begin{array}{c}\text { BPA } \\
(n=4-6)\end{array}$ \\
\hline $\operatorname{Tnf} \alpha$ & $1.031 \pm 0.29$ & $\begin{array}{c}16.76 \pm 1.071 * \\
(p=0.042)\end{array}$ & $1.026 \pm 0.27$ & $\begin{array}{c}2.54 \pm 1.09 * \\
(p=0.0043)\end{array}$ \\
\hline Il-6 & $1.079 \pm 0.62$ & $\begin{array}{c}14.99 \pm 5.6^{*} \\
(p=0.041)\end{array}$ & $1.094 \pm 0.48$ & $\begin{array}{c}1.071 \pm 0.98 \\
(p=0.87)\end{array}$ \\
\hline$N f-k b$ & $1.15 \pm 0,30$ & $\begin{array}{c}10,68 \pm 4.1 * \\
(p=0.043)\end{array}$ & $1.19 \pm 0.4$ & $\begin{array}{c}2.31 \pm 0.93 * \\
(p=0.012)\end{array}$ \\
\hline
\end{tabular}

Data are expressed as normalised fold expression \pm SD. * Statistically significant difference vs. control group.

\subsubsection{Oxidative Stress}

The mitochondrial manganese superoxide dismutase (MnSOD or SOD2), a key biomarker of oxidative stress, was analysed by Western blot (Figure 4). The enzyme expressed in both lactating and young animals did not show any statistically significant difference related to age, sex, or treatment.

\section{A}

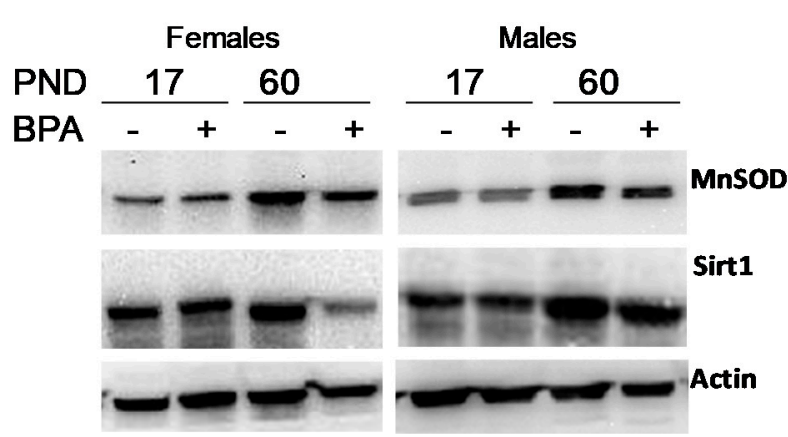

B

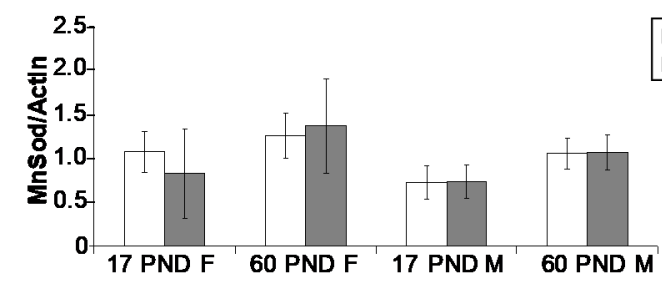

D

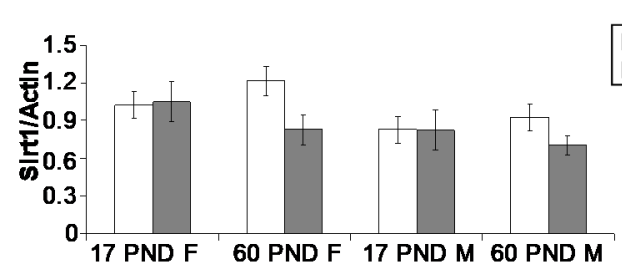

C
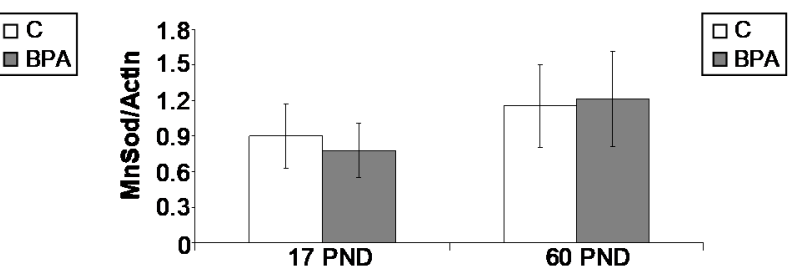

E
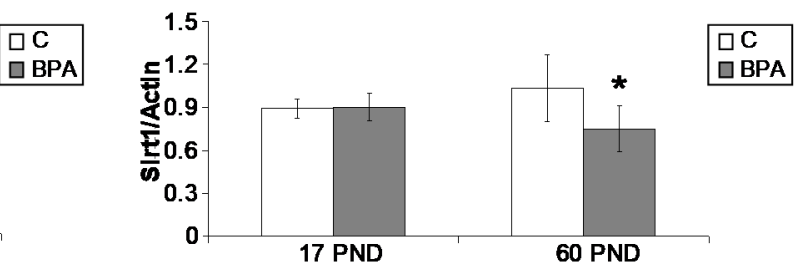

Figure 4. Representative Western blot for MnSOD and Sirt1 carried out in liver samples collected from lactating and young animals. (A). Data were normalised against actin- $\beta$, and are reported in (B-E) as mean value $\pm \mathrm{SD}(n=3$ in $\mathrm{B}$ and $\mathrm{D}, n=6$ in C and E, 3 males and 3 females). F: females; M: males; PND: postnatal day. ${ }^{*} p=0.0143$. 


\subsubsection{Epigenetics and Epigenetic Machinery}

Sirt1 protein was analysed by Western blot in lactating and young animals (Figure 4). The protein resulted in being constantly expressed in lactating animals (17 PND); however, a significant decrease was observed only in 60 PND BPA treated animals $(p<0.05)$.

Therefore, the expression profile of Sirt1 mRNA was further investigated at 60 PND by qPCR, confirming that Sirt1 mRNA in BPA treated animals was significantly lower $(p<0.05)$ than the control group in both sexes (Figure 5A,B).

Since the evidence in the literature revealed the presence of Sirt1 natural antisense long non-coding RNA (Sirt1-AS LncRNA), an endogenous modulator of Sirt1 mRNA stability in mouse [38,39] and human [40] rising from Sirt1 gene $3^{\prime}$ end, Sirt1 sequence was compared in rodents (mouse vs. rat, $97 \%(262 / 271)$ nucleotide identity in the gene region responsible for the formation of Sirt1-AS LncRNA. Hence, the possible presence of Sirt1-AS LncRNA was investigated in rat tissues [heart, positive control, and testis from control animals; liver from control and BPA exposed animals] by strand-specific PCR (Figure 5C). A band of the predicted size of $124 \mathrm{bp}$ was detected in all tested tissues, particularly in the testis of control animals and in the liver of BPA exposed animals. Therefore, the expression rate of Sirt1-AS LncRNA was analysed by qPCR, revealing significantly higher expression in the liver of young animals, without any sex-dependent difference (Figure 5D,E).

A

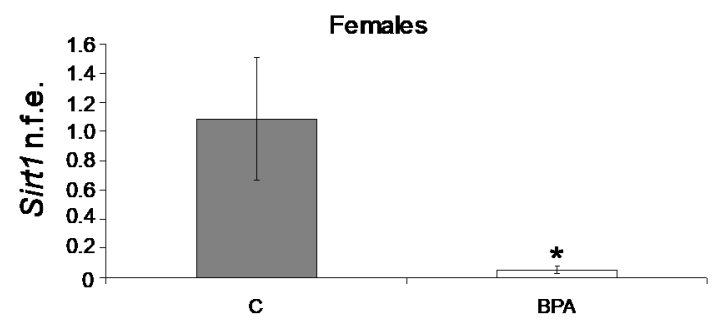

C

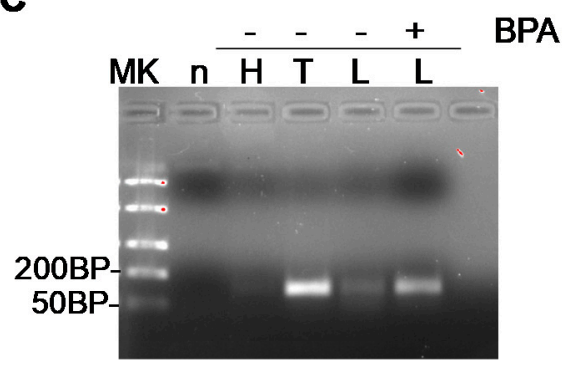

D

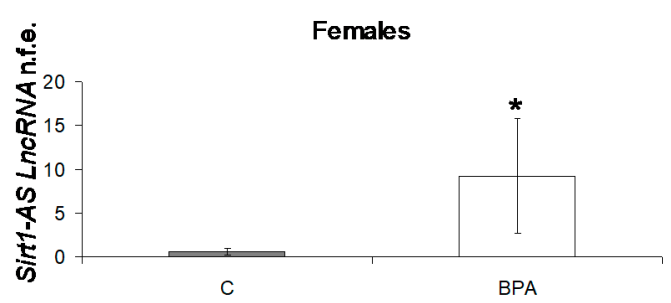

B

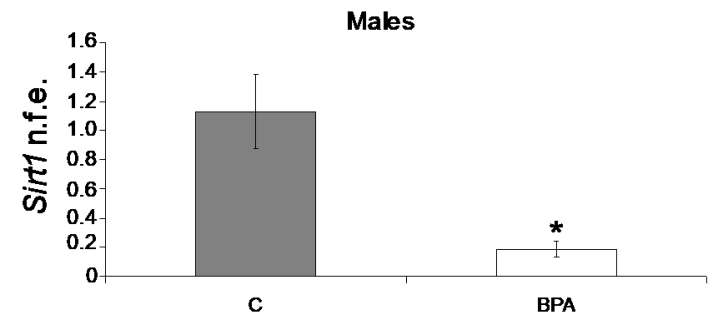

E

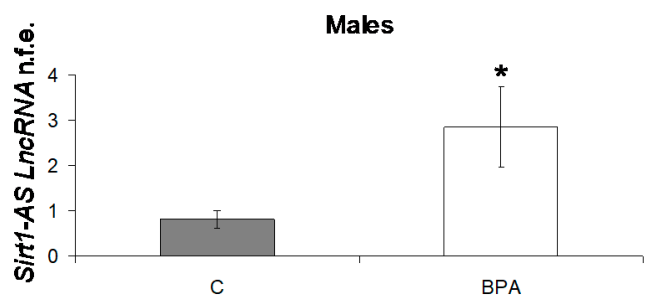

Figure 5. Sirt1 qPCR in male (A) and female young animals (60 PND) (B). Strand-specific PCR for the detection of Sirt1-AS LncRNA in rat tissues (MK, DNA ladder; $\mathrm{n}$, negative control; $\mathrm{H}$, heart, $\mathrm{T}$, testis; $\mathrm{L}$, liver; -BPA absence; + BPA presence) (C). Quantitative PCR analysis for Sirt1-AS LncRNA in male (D) and female young animals (60 PND) (E). qPCR data are expressed as normalized fold expression (n.f.e.) \pm SE, reference gene Gapdh; reference sample arbitrarily assigned value 1 , control group $\left(n=6,3\right.$ males and 3 females, $\left.{ }^{*} p<0.05\right)$. 
In addition, the expression rate of the main enzymes involved in maintaining and de novo establishment of DNA methylation, Dnmt1 and Dnmt3a, respectively, in parallel to histone deacetylases Hdac1 and Hdac2 were analysed by qPCR in young animals (Table 4).

Table 4. Expression analysis of epigenetic biomarkers in weaned (60 PND) animals.

\begin{tabular}{|c|c|c|c|c|}
\hline \multirow[b]{2}{*}{ mRNA } & \multicolumn{2}{|c|}{60 PND Females } & \multicolumn{2}{|c|}{60 PND Males } \\
\hline & $\begin{array}{c}\text { Control } \\
(n=3)\end{array}$ & $\begin{array}{c}\text { BPA } \\
(n=3)\end{array}$ & $\begin{array}{c}\text { Control } \\
(n=3)\end{array}$ & $\begin{array}{c}\text { BPA } \\
(n=3)\end{array}$ \\
\hline Dnmt1 & $1.110 \pm 0.65$ & $\begin{array}{c}0.416 \pm 0.36 \\
(p=0.181)\end{array}$ & $1.164 \pm 0.73$ & $\begin{array}{c}0.834 \pm 0.42 \\
(p=0.359)\end{array}$ \\
\hline Dnmt3a & $1.145 \pm 0.768$ & $\begin{array}{c}0.601 \pm 0.57 \\
(p=0.387)\end{array}$ & $1.039 \pm 0.52$ & $\begin{array}{c}1.049 \pm 0.35 \\
(p=0.985)\end{array}$ \\
\hline Hdac1 & $1.177 \pm 0.25$ & $\begin{array}{c}4.477 \pm 0.75^{*} \\
(p=0.002)\end{array}$ & $1.112 \pm 0.35$ & $\begin{array}{c}1.823 \pm 0.15 * \\
(p=0.019)\end{array}$ \\
\hline Hdac2 & $1.16 \pm 0.64$ & $\begin{array}{c}0.866 \pm 0.18 \\
(p=0.483)\end{array}$ & $1.05 \pm 0.41$ & $\begin{array}{c}1.56 \pm 0.22 \\
(p=0.332)\end{array}$ \\
\hline
\end{tabular}

Data are expressed as normalised fold expression $\pm \mathrm{SD} .{ }^{*}$ Statistically significant difference vs. control group.

Dnmt1 and Dnmt3a mRNA levels were constant in young BPA exposed animals. However, the expression level of Dnmt1 was slightly lower in young animals, but this difference was not statistically significant.

Hdac1 mRNA was significantly higher in the treated animals, particularly in female rats. Hdac2 expression level remained constant in young animals, but a different expression trend was observed in females and males.

\subsubsection{Lipid and Glucose Metabolism}

The expression rate of glucose-6-phosphatase (G6Pase), Steroidogenic Acute Regulatory Protein (StAR), and Liver X receptor alpha ( $L X R a)$ was analysed by qPCR and was constant in control and BPA exposed young weaned animals (Table 5).

Table 5. Expression analysis of lipid and glucose metabolism biomarkers in weaned animals.

\begin{tabular}{ccc}
\hline mRNA & $\begin{array}{c}\text { Control } \\
(\boldsymbol{n}=\mathbf{4}-\mathbf{6})\end{array}$ & $\begin{array}{c}\text { BPA } \\
(\boldsymbol{n}=\mathbf{4}-\mathbf{6})\end{array}$ \\
\hline G6Pase & $1.047 \pm 0.331$ & $\begin{array}{c}1.251 \pm 0.82 \\
(p=0.606)\end{array}$ \\
\hline Star & $1.105 \pm 0.299$ & $\begin{array}{c}0.809 \pm 0.151 \\
(p=0.426)\end{array}$ \\
\hline LXRa & $1.077 \pm 0.41$ & $\begin{array}{c}1.025 \pm 0.38 \\
(p=0.828)\end{array}$ \\
\hline
\end{tabular}

Data are expressed as normalised fold expression \pm SD.

\section{Discussion}

In recent years, the impact of BPA exposure on health has received more and more attention. This widely used environmental pollutant interferes in the homeostasis of the endocrine system causing developmental, reproductive, inflammatory, and metabolic dysfunction in humans and animals [2,3,5-10]. Epidemiological studies revealed significant urinary BPA concentration in large populations [41] and the correlation between BPA exposure and the development of chronic diseases [42,43], suggesting health risk. Nevertheless, BPA effects strongly depend on life stage, doses, exposure route, or time as well, with exposure in early life more deleterious than exposure in adult life [1,44]. Currently, its concrete risk for health is debated [45], and in several countries, its use has been restricted for some articles like infant feeding bottles [46]. The development of BPA substitutes like 
Bisphenol B (BPB), Bisphenol F (BPF), Bisphenol S (BPS), or Bisphenol AF (BPAF) did not help in solving BPA-related issues as preliminary studies have revealed these BPA analogues are not fully safe for health [14,47-49]. Therefore, additional studies on BPA mimicking human exposure routes (i.e., oral exposure by food or beverage) and doses currently considered "safe" for health are needed.

In the present study, we chronically exposed rats to BPA, first during the gestational and lactating phase through the administration of BPA in drinking water to dams; then, at weaning, the offspring were assigned to the same treatment groups as their mothers and started receiving BPA or vehicle in drinking water. Daily exposure dose of $10 \mu \mathrm{g} / \mathrm{kg}$ bw has been predicted accordingly to daily consumption of drinking water. Since the European Food Safety Authority (EFSA) has established tolerable daily intake (t-TDI) of $4 \mu \mathrm{g} / \mathrm{kg}$ bw-day, against the $50 \mu \mathrm{g} / \mathrm{kg}$ bw-day in the USA [50,51], the BPA dose used in this study is within the reference limit for humans, currently considered "safe" for health. We found circulating free and BPA-G levels in both lactating and weaned young animals, including control groups, probably as a consequence of general environmental exposure. However, both free and BPA-G levels resulted significantly higher than control groups only in animals exposed to BPA during lactation; similarly, lactation is the only exposure window with significant bio-accumulation of BPA in white adipose tissue. BPA bio-accumulates in maternal milk [13]. In infant rats and mice, the ability of the liver to conjugate BPA is limited, and in humans, BPA body burden decreases with age and intake rates are higher in children and adolescents than in adults [52]. In this respect, the lactation phase deserves particular attention for the health risk related to BPA exposure. In fact, maternal milk may represent an important vehicle for BPA transfer from mother to offspring in a time frame critical for the developmental process and possible disease load in later life. Thus, BPA has generated considerable concern, and in the present manuscript, the brain and liver were chosen as target tissues to evaluate the effects of BPA chronic exposure.

The developing brain is a particularly sensitive BPA target [5]. Present data reveals significant enlargement of the lateral ventricles in the brains of both lactating and weaned rats, suggesting BPA interference in postnatal brain development and brain functions in adult life. Consistently, in the same cohort of lactating animals used in this study, BPA exposure induced DNA damage in microglia and astrocytosis by decreasing ER $\alpha$ expression within the dentate gyrus, thus altering immune surveillance functions within the brain [20]. Ventricle enlargement may be the consequence of increased cerebrospinal fluid (CSF) pressure and circulation, especially in the "vulnerability window" of brain development [53]. The CSF maintains brain homeostasis, supplies nutrients and is an important source of biologically active molecules involved in stem cell proliferation, brain development, differentiation, and repair [54,55]. In this respect, CSF also functions as a lymphatic system for the brain, and CSF compartments are key to the immune surveillance of the Central Nervous System (CNS) $[55,56]$. Finally, CSF regulates intracranial pressure, playing an important role in volume transmission within the developing and adult brain [54]. Dysfunctions in the CSF circulation and in the size of cerebral ventricles are known to be linked to various pathologies such as hydrocephalus, encephalopathy, degenerative disease, and so on [57]. The significance of such a variation is still controversial, but some Authors have suggested that changes in the size and morphology of lateral ventricles may be related to subcortical white and/or grey matter alterations $[57,58]$.

During pregnancy, BPA exposure may affect the health of both mother and offspring, causing excess body weight, insulin resistance, and hyper-insulinemia in the mothers and altered glucose homeostasis, increased weight, and adipogenesis in the offspring, which can display obese phenotype, glucose intolerance, and insulin resistance at adult age [44]. In the present study, the BPA exposed offspring did not display any significant changes in body weight gain during the lactating phase or as young animals. However, in 45 PND exposed animals, a significant increase in body weight was registered in male rats in relation to puberty and sex maturation [27]. Most histological features of the liver were normal over all 
the treatment without any significant differences related to age, sex, and diet (i.e., maternal milk vs. standard diet for weaned animals); mild microvesicular steatosis was present in all groups except in the control lactating group, and statically not significant hypertrophy was observed in all BPA exposed animals. Despite lacking macroscopical tissue alterations, at the molecular level, BPA is able to exert high stimulatory effects on the expression rate of inflammatory cytokines (i.e., Tnf $\alpha$ and $I l-6$ ) and $N f-k b$-mediated inflammation in lactating exposed offspring. BPA effects on gene expression were still persistent, but on a lighter level, in weaned young animals with $T n f \alpha$ and $N f-k b$ mRNA slightly over-expressed with respect to the control group and Il-6 expressed at levels comparable to the corresponding control group. Taken together, our results suggest that the lactating period remains a critical exposure window, whereas a partial rescue can occur in young animals.

Notably, oxidative stress is the main consequence of BPA exposure $[3,5,27]$, but, consistent with the morphological evaluation of the liver provided here, SOD2 protein, the main mitochondrial biomarkers of antioxidant defences against reactive oxygen species, was constantly expressed in the liver of lactating and young animals, confirming that the used BPA dose falls within the range of "safe dose" for health. By contrast, the metabolic sensor Sirt1 resulted in being a BPA target in both rat testis [27] and liver (present data). In the liver of young but not lactating exposed animals, Sirt1 protein resulted expressed at lower levels than control groups providing evidence for a possible predisposition to the occurrence of impairment in Sirt1-downstream pathways. In the liver, Sirt1 plays a beneficial role in regulating lipid metabolism and controlling oxidative stress and inflammation by deacetylating some transcriptional regulators against the progression of fatty liver disease [37]. Sirt1 liver-specific knockout causes hepatic steatosis and promotes the progression to advanced metabolic disorders [37]. In our experimental model, microvesicular steatosis occurred in BPA-exposed lactating animals with the partial rescue of inflammation biomarkers at weaning. Sirt1 is a well-known suppressor of TNF $\alpha$ induced apoptosis [59]. Loss of Sirt1 activity regulates the expression of Il-6 [60], and as reported above, these inflammatory cytokines resulted in being differently expressed in the liver of the BPA-treated animals collected at different ages. Interestingly, antagonistic crosstalk between Nf-kb and Sirt1 in the regulation of inflammation and metabolic disorders have been reported, with Sirt1 inhibition capable of disrupting oxidative energy metabolism and stimulating the $\mathrm{Nf}-\mathrm{kb}$-induced inflammatory responses that characterise several age-related and chronic metabolic diseases [61].

Natural antisense transcripts (NATs), originally considered as transcriptional noises arising from "junk DNA", are recently recognised as important players in the epigenetic regulation of gene expression [62]. Recent studies demonstrated a self-modulatory loop in Sirt1 activity involving its NAT, the Sirt1-AS LncRNA. This natural antisense long noncoding RNA is transcribed from the Sirt1 gene antisense strand [38] and rescues Sirt1 transcriptional suppression through the formation of an RNA-RNA duplex with the $3^{\prime}$ untranslated region of Sirt1 mRNA [39]. In mice, this pathway inhibits Sirt1 silencing mediated by $m i R-34 a$ and promotes the stability of Sirt1 mRNA during myogenic differentiation [39]; furthermore, it attenuates pulmonary fibrosis, enhancing the stability of Sirt1 and increasing its expression during the epithelial-mesenchymal transition [63]. In humans, Sirt1-AS LncRNA suppressed the miRNA-induced translational repression of Sirt1 mRNA by masking the miR-29c binding site on the Sirt1 $3^{\prime}$ untranslated region and promoting the proliferation of the human hepatocellular carcinoma (HCC) cell lines [40]. Furthermore, the Sirt1 AS transcript was down-regulated in human tumours, while the Sirt1 mRNA level was increased in cancer cell lines and cancer tissues [64]. In this paper, by specific stand PCR, we provide evidence of Sirt1-AS LncRNA in the heart (positive control), testis and liver of 60 PND rats. The decreased expression of Sirt1 in the liver of BPA-exposed weaned rats (both females and males) parallels the increased expression rate of Sirt1-AS LncRNA, confirming the existence of a functional relationship between Sirt1 mRNA and its AS transcript. 
The epigenetic effects of BPA usually occur through changes in DNA methylation status, histone protein modifications, or the aberrant production of non-coding RNA [3]. Present data revealed that BPA treatment did not affect the expression rate of maintaining and de novo DNA methylation enzymes (i.e., Dnmt1 and Dnmt3a), which are notably involved in the BPA dependent occurrence of insulin resistance, hepatic lipid accumulation, and steatosis in adulthood via aberrant methylation status in the promoter region of genes involved in glucose and lipid homeostasis $[25,65,66]$. Conversely, HDAC1 mRNA resulted in being significantly higher in the exposed weaned animals. In this respect, the interaction between Sirt1 and other epigenetic markers/enzymes has been reported. Histones H1, H3, and H4, Dnmt1, and Hdac1 are well-known targets of Sirt1 [30], and during heat-shock stress, the acetylation of Hdac1 and the degradation of Sirt1 form a positive feedback loop to regulate p53 activity, one of the main downstream targets of Sirt1 related to apoptosis [67].

Thus in our system, a double route involving Sirt1-AS LncRNA and Hdac1 and aimed at compensating hepatic Sirt1 deficit may be suggested. Accordingly, the present study revealed that BPA exposed weaned animals did not exhibit any significant alterations in the expression rate of G6Pase and LXRa- targets of Sirt1protein [68,69], and Star that are involved in glucose homeostasis, bile acid synthesis, intracellular lipid homeostasis, cholesterol metabolism, and in the control of transcriptional programs critical for lipid homeostasis and inflammation. However, preliminary results from liquid chromatographymass spectrometry and infrared spectroscopy limited to the cohort of 60 PND male rats used in this study revealed that the liver of sexually mature male rats chronically exposed to BPA had a different lipid and carbohydrate composition than the control [70], raising the possibility of metabolism-related disease load in later life. The decreased levels of Sirt1 (both mRNA and protein), a leader in the protective mechanisms against disease-related conditions, confirms the health risk of BPA exposure at low doses.

Thus, the present study gave evidence of the toxic effects of BPA from a low-dose drinking source, with particular emphasis on the risk during lactation and confirmed Sirt1 as a key epigenetic target of environmental exposure to toxicants. However, the present work did not evaluate a dose-response curve of BPA effects and did not obtain a direct measure of BPA levels in milk. These points could eventually be evaluated in future studies in parallel to the metabolic and neurological status of the older animals.

The interaction between diet quality and lean vs. overweight/obese phenotypes on BPA health effects is an additional interesting perspective to take into account. In fact, in animal models, BPA maternal nutrient supplementation counteracts BPA-induced DNA hypomethylation in early development, and dietary intervention, like the administration of antioxidants, could mitigate some of BPA's adverse effects on health $([3,10]$ for review). Nevertheless, in humans, the association between overweight/obese phenotypes on BPA health effects is suggested [42,43] but still controversial due to the limited number of epidemiological and toxicological studies, sometimes revealing contradictory results. Therefore, additional studies are required in this field.

\section{Materials and Methods}

\subsection{Chemicals and Antisera}

BPA (Sigma Aldrich, Milan, Italy) was dissolved in ethanol $(0.1 \mathrm{mg}$ BPA/100 $\mu \mathrm{L}$ ethanol) and added to one litre of drinking water as previously reported [27]. In Western blot, primary antisera were: mouse monoclonal anti-Sirt1 diluted 1:5000 (ab110304; Abcam, Cambridge, MA, USA); anti-MnSOD diluted 1:1000 (06-984, Merck Millipore Milan, Italy); mouse monoclonal anti Actin- $\beta$ diluted 1:2000 (A3853, Sigma Aldrich). Horse-radish conjugated secondary antisera (Santa Cruz Biotechnology Inc., Heidelberg, Germany) were used at 1:1000 dilution.

\subsection{Animals and BPA Exposure Protocol}

In vivo exposure of pregnant Wistar rats $(n=6)$ (Harlan Laboratories, Udine, Italy) was carried out as recently reported [37]. Each female was housed in a separate cage 
and was given in drinking water treatment [0.1 mg BPA dissolved in $100 \mu \mathrm{L}$ ethanol for litre; BPA-exposed mothers, $n=3)$ or vehicle $(100 \mu \mathrm{L} / 1$ ethanol; control mothers, $n=3)$ ] by glass bottles. This treatment was expected to result in a daily BPA exposure of $10 \mu \mathrm{g} / \mathrm{Kg}$ b.w. for the treated group and $0 \mu \mathrm{g} / \mathrm{Kg}$ b.w. for the control group (considering an average daily water intake of $0.1 \mathrm{~L} / \mathrm{Kg}$ b.w.). This treatment was maintained all the time also for the newborns, assigning each newborn to the same treatment group of the mother. Newborns were finally sacrificed at 10-17 postnatal day (PND) (BPA-exposed lactating group, $n=7$ males, 6 females, and control lactating group, 6 males, 5 females) or at 45-60 PND (BPA-exposed young group, 10 males, 9 females, and control young group, 9 males, 7 females) following deep anaesthesia by an overdose of Tanax $(0.1 \mathrm{~mL}$ intrapulmonary). Peripheral blood was collected, centrifuged to gain plasma, and stored at $-80{ }^{\circ} \mathrm{C}$ until used for the measure of free BPA and BPA-G. Visceral adipose tissue and liver pieces were removed, quickly frozen in dry ice and stored at $-80{ }^{\circ} \mathrm{C}$ until used for Reverse Transcriptase-quantitative Polymerase Chain Reaction (RT-qPCR), Western blot, or for BPA measure, as reported below. After that, animals were perfused with $4 \%$ paraformaldehyde (PFA), and fixed brain and liver pieces were collected and processed for histological evaluations. Hearts and testis were also collected from $n=3$ vehicle-treated young animals (60 PND) and used as a positive control.

For the entire experiment, animals were housed under standard conditions with free access to fresh food with minimised levels of naturally-occurring phytoestrogens (Teklad Global Rodent Diets, Envigo, Italy) and tap water (with BPA added or vehicle as described) according to the EU norm for the use and care of experimental animals. The experimental protocol was approved by the Ethical Committees of the University of Salerno and by the Italian Ministry of Education, University and Research (authorisation number: 45/2014-PR 17 November 2014).

\subsection{Free and Conjugate Plasma BPA Measure}

BPA determinations were conducted as reported by Kosarac et al. [71], with some minor modifications as reported in [72,73]. Briefly, d16-BPA was added as an internal standard and samples were defatted with hexane and then extracted with dichloromethane. The extracts were purified in two successive SPE steps, one with a Florisil solid phase and one with a C18 solid phase. Deconjugation was carried out using $\beta$-Glucuronidase/Arylsulfatase from Helix pomatia (Sigma-Aldrich). After nitrogen drying, purified serum extracts were derivatised with N,O-Bis(trimethylsilyl)trifluoroacetamide (BSTFA) (Sigma-Aldrich). Derivatised samples were quantified using triple quadrupole mass spectrometer hyphenated with gas chromatography by means of GCMS TQ8030 (Shimadzu, Kyoto, Japan).

The gas chromatographic method was based on a SLB- $5 \mathrm{~ms}, 10 \mathrm{~m} \times 0.1 \mathrm{~mm}$, with a film thickness of $0.1 \mu \mathrm{m}$ (Supelco, Milan, Italy). The GC oven program includes an initial phase of $1.5 \mathrm{~min}$ at $188^{\circ} \mathrm{C}$ and two ramps: the first at $20^{\circ} \mathrm{C} / \mathrm{min}$ up to $260{ }^{\circ} \mathrm{C}$, the second at $40{ }^{\circ} \mathrm{C} / \mathrm{min}$ up to $320^{\circ} \mathrm{C}$. The injection temperature was set at $260{ }^{\circ} \mathrm{C}$, and the linear velocity of the carrier gas $(\mathrm{He})$ was $70 \mathrm{~cm} / \mathrm{s}$. The total analytical time was $8 \mathrm{~min}$. Two acquisition channels were used, one in SCAN mode between $m / z=50$ and $m / z=500$ and one in MRM mode: $357.10>191.20 \mathrm{~m} / z$ for BPA and $370.50>73.10 \mathrm{~m} / z$ for the d16-BPA.

\subsection{Adipose Tissue BPA Measure}

An aliquot of $100 \mathrm{mg}$ of adipose tissue from each sample was homogenised with $500 \mu \mathrm{L}$ of water using an Ultra-Turrax ${ }^{\circledR}\left(\mathrm{IKA}^{\circledR}\right.$ T18 Basic) and spiked with d16-BPA as internal standard. Calibrant samples were prepared in adipose tissue by spiking tissue homogenate with a known volume of BPA solution to obtain final concentrations ranging from $0.1 \mathrm{ng} / \mathrm{mL}$ to $10.0 \mathrm{ng} / \mathrm{mL}$. For calibration blanks and samples, fortifications were replaced with an aliquot of pure methanol. Five hundred microliters of acetonitrile were added to samples homogenates and then vortex-mixed for $1 \mathrm{~min}$. A buffer solution containing magnesium sulphate, di and trisodium citrate, and sodium chloride was added, and $\mathrm{pH}$ was adjusted to 5.5 with $\mathrm{NaOH} 1 \mathrm{M}$. Solutions were vortex-mixed again for $1 \mathrm{~min}$ 
and centrifuged. The upper organic layer was added with $100 \mathrm{mg}$ of diamino, primary secondary amine octadecyl modified silica phase end-capped (Machery-Nagel, Düeren, Germany), vortexed again for $30 \mathrm{~s}$ and centrifuged at $2500 \times g$ for $5 \mathrm{~min}$. The purified upper organic layer was transferred into a clean glass tube and evaporated to dryness at $37^{\circ} \mathrm{C}$ under a gentle nitrogen stream. Dry residues were derivatised and analysed as for serum samples.

\subsection{Nissl Staining and Measurement of Ventricle Size}

Brains ( $n=5$ /group, 3 females and 2 males) were removed, post-fixed overnight in $4 \%$ PFA, and transferred in $70 \%$ ethanol until they were included in paraffin. Serial $10 \mu \mathrm{m}$ coronal sections were sampled according to the atlas of Paxinos and Watson [74] and collected onto glass slides. Deparaffinised sections were then processed for staining with Nissl staining. Briefly, after rinsing in $\mathrm{dH}_{2} \mathrm{O}$, sections were incubated for $8 \mathrm{~min}$ in thionin. The sections were then dehydrated through serial ethanol solutions (70 to 100\%), cleared in xylene and mounted with Eukitt ${ }^{\circledR}$ Quick-hardening mounting medium. Sections were imaged for bright-field microscopy using an upright microscope (Olympus BX53). Areas of lateral ventricle were manually traced from both sides, measured using ImageJ, and volumes were recorded in square millimetres.

\subsection{Evaluation of Liver Morphology}

PFA fixed livers were processed for paraffin embedding accordingly to standard procedures. Sections $(5 \mu \mathrm{m})$ were mounted on slides and stained with haematoxylin and eosin for histological analysis. Histological features were evaluated using the General NAFLD Scoring System for Rodent Models [75] and were grouped into four broad categories: macrovesicular steatosis, microvesicular steatosis, hypertrophy, and inflammation. A modified Kleiner scoring [76] was used as summarised in Table 6.

Table 6. NAFLD Scoring System for Rodent Models.

\begin{tabular}{cccccc}
\hline \multirow{2}{*}{ Histological Feature } & \multicolumn{4}{c}{ Score } \\
\cline { 3 - 5 } & & $\mathbf{0}$ & $\mathbf{1}$ & $\mathbf{2}$ & $\mathbf{3}$ \\
\hline \multirow{3}{*}{ Steatosis } & macrovesicular steatosis & $<5 \%$ & $5-33 \%$ & $33-66 \%$ & $>66 \%$ \\
\cline { 2 - 5 } & microvesicular steatosis & $<5 \%$ & $5-33 \%$ & $33-66 \%$ & $>66 \%$ \\
\cline { 2 - 6 } Inflammation & hypertrophy & $<5 \%$ & $5-33 \%$ & $33-66 \%$ & $>66 \%$ \\
\hline & $\begin{array}{c}\text { number of inflammatory } \\
\text { foci/field }\end{array}$ & $<0.5$ & $0.5-1.0$ & $1.0-2.0$ & $>2.0$ \\
\hline
\end{tabular}

\subsection{Protein Extraction and Western Blot}

The liver was homogenised with a dunce homogeniser at $4{ }^{\circ} \mathrm{C}$ in ice-cold RIPA buffer ( $3 \mathrm{~mL} / \mathrm{g}$ tissue, added with protease inhibitor cocktail, all from Santa Cruz Biotechnology). After the addition of $300 \mu \mathrm{g}$ of Phenylmethylsulfonyl fluoride (PMSF) per gram of tissue, lysate was kept in ice for $30^{\prime}$ and then centrifuged twice at $10,000 \times g$ for $10 \mathrm{~min}$ at $4{ }^{\circ} \mathrm{C}$ to gain total proteins extract in cleared supernatant. Protein concentration was then determined using the Lowry method [77].

Proteins $(40 \mu \mathrm{g})$ were resolved by 8 or $12 \%$ sodium dodecyl sulfate-polyacrylamide gel (SDS-PAGE) and transferred into PVDF filters by Trans-Blot Turbo Transfer System (Bio-Rad Laboratories, Inc. Hercules, CA, USA). Filters were then stripped in Western blot stripping buffer (Santa Cruz Biotechnology Inc.) and reprobed with actin- $\beta$ to normalise protein signals. Images were obtained by ChemiDoc-it 500 Imaging System (Bio-Rad Laboratories), and the optical density of the bands was analysed with Quantity One Analysis Software (Bio-Rad Laboratories). Data were expressed as mean protein $/ \alpha$-actin ratio $\pm \mathrm{SD}$. 


\subsection{Total RNA Extraction, Quantitative Reverse Transcription Polymerase Chain Reaction (qRT-PCR)}

Total RNA was extracted from the liver, heart, and testis of weaned animals by RNA-XPress Reagent (Himedia, Mumbai, India) following the manufacturer's instructions. Following DNaseI treatment (Thermo Fisher Scientific, Milan, Italy), $5 \mu \mathrm{g}$ total RNA were reverse transcribed using a mixture of $\mathrm{dT}_{18} /$ random examers by SuperScript-III RNase $\mathrm{H}^{-}$ Reverse Transcriptase (Thermo Fisher Scientific) in a total volume of $20 \mu \mathrm{L}$ and following the instructions of the manufacturer.

All qRT-PCR assays were prepared in a final volume of $20 \mu \mathrm{L}$ containing $1 \mu \mathrm{L}$ of 1:5 diluted cDNA, $0.5 \mu \mathrm{M}$ specific primer (details in Table 7), and $10 \mu \mathrm{L}$ of SYBR Green Master Mix (Bio-Rad Laboratories). Each assay was carried out twice in duplicates in the Mastercycler CFX-96 (Bio-Rad Laboratories) and included melting curve analysis. The expression rate was normalised against actin- $\beta$ or Gapdh by the ${ }^{\Delta \Delta} \mathrm{Ct}$ method as previously described [78]. Data were then reported as mean fold change \pm S.D. over the value one arbitrarily assigned to the control sample.

\subsection{Evaluation of Sirt1-AS LncRNA: Strand Specific PCR and Expression Analysis}

Following DNaseI treatment, $5 \mu \mathrm{g}$ total RNA were reverse transcribed as reported in the previous paragraph substituting the mixture of $\mathrm{dT}_{18} /$ random examers with $0.5 \mu \mathrm{M}$ of the reverse primer of Sirt1-AS IncRNA (Table 7). Strand-specific RT-PCR was carried out using the $1 \mu \mathrm{L}$ of diluted (1:5) cDNA, $10 \mathrm{pMol}$ oligonucleotide primers (Table 7) in PCR mix [0.2 mM dNTP, $1 \times$ PCR buffer, $1.5 \mathrm{mM} \mathrm{MgCl2}$, $1.25 \mathrm{U}$ Taq Polymerase (Thermo Fisher Scientific)], using a DNA Engine ThermalCycler (Bio-Rad Laboratories) at the following conditions: $5^{\circ} \mathrm{C} 30 \mathrm{~s}, 60^{\circ} \mathrm{C} 30 \mathrm{~s}, 72{ }^{\circ} \mathrm{C} 30 \mathrm{~s}$ for 30 cycles; $\mathrm{PCR}$ products were checked on $2 \%$ agarose gel to reveal an amplificate of the predicted size of $124 \mathrm{bp}$.

Table 7. Primers used in the study.

\begin{tabular}{|c|c|c|c|c|}
\hline & Target & Forward $5^{\prime}-3^{\prime}$ & Reverse $5^{\prime}-3^{\prime}$ & \\
\hline \multirow{3}{*}{ Inflammation } & Tnfo & ACTGATGAGAGGGAGCCCAT & CTGTGCCTCAGCCTCTTCTC & qRT-PCR \\
\hline & II-6 & AGTCTCCTCTCCGGACTTGT & AGAGACTTCCAGCCAGTTGC & qRT-PCR \\
\hline & $N f-k b$ & TCACTGAGCTCCCGATCAGA & CATACGCTGACCCTAGCCTG & qRT-PCR \\
\hline \multirow{8}{*}{ Epigenetics } & Sirt1 & CACCAGAAAGAACTTCACCACCAG & ACCATCAAGCCGCCTACTAATCTG & qRT-PCR \\
\hline & Sirt1-AS IncRNA & TCACATCATGCAAATGGAAAACTAA & TAGGACCATTACTGCCAGAGGA & Strand specific PCR \\
\hline & Sirt1-AS lncRNA & TCACATCATGCAAATGGAAAACTAA & TAGGACCATTACTGCCAGAGGA & qRT-PCR \\
\hline & Sirt1-AS IncRNA & - & TAGGACCATTACTGCCAGAGGA & RT \\
\hline & Dnmt1 & CTTTTTGGGTGACGGCAACTC & GCTAAGGACGATGATGAGACGC & qRT-PCR \\
\hline & Dnmt3a & CAGCGTCACACAGAAGCATATCC & GGTCCTCACTTTGCTGAACTTGG & qRT-PCR \\
\hline & Hdac1 & ATTGGAAGGGCTGATGTG & AATGCTAATGTTGGGAGG & qRT-PCR \\
\hline & Hdac2 & GCTATCCGCTTGTCTGATGCTC & CAGTTGCCCTTGATTGTGAGATTC & qRT-PCR \\
\hline \multirow{3}{*}{ Metabolism } & $L X R a$ & AGGGCTCCAGGAAGAGATGT & AACTCCGTTGCAGAGTCAGG & qRT-PCR \\
\hline & G6Pase & CGTCACCTGTGAGACTGGAC & ACGACATTCAAGCACCGGAA & qRT-PCR \\
\hline & Star & GCTGGCGAACTCTATCTGGGT & GGGAGATGCCTGAGCAAAGC & qRT-PCR \\
\hline \multirow{2}{*}{ Housekeeping } & Actin- $\beta$ & AGATGACCCAGATCATGTTTGAGA & ACCAGAGGCATACAGGGACAA & qRT-PCR \\
\hline & Gapdh & TGGAGTCTACTGGCGTCTT & TGTCATATTTCTCGTGGTTG & qRT-PCR \\
\hline
\end{tabular}

\subsection{Statistical Analysis}

Data were expressed as mean \pm standard error (SE) or standard deviation (SD). Student's $t$-test was performed evaluating the differences between BPA exposed groups and controls. Comparisons between multiple groups were assessed by two-way ANOVA followed by Tukey's post hoc test for parametric data or by the Kruskal-Wallis and the Mann-Whitney U tests for non-parametric data. Statistical analysis was performed with GraphPad Prism software (version 5.0, GraphPad Software, San Diego, CA, USA). A $p<0.05$ was considered statistically significant. 


\section{Conclusions}

The present study shows that chronic exposure to a low BPA dose could increase the risk for disease load in adult life as a consequence of higher BPA circulating levels and accumulation in adipose tissue during the neonatal period. In the same cohort of animals used in this study, impairment of immune surveillance functions in the brain of lactating animals [20], the defective first round of spermatogenesis [37], and altered liver composition in adult male rats [70] have been reported. In this respect, the effects on cerebral ventricle enlargement observed here over the treatment may affect long-term brain homeostasis and physiology. Similarly, the occurrence of mild to moderate liver microvesicular steatosis, in parallel to the decreased levels of the epigenetic biomarker Sirt1 in weaned animals only, point out the need for long-term monitoring of the neurological and metabolic health status of the exposed animals. Possible epigenetic mechanisms occurring via Sirt1-AS LncRNA and Hdac1 may be suggested in the liver.

In conclusion, the lactating phase represents the main window of vulnerability for BPA dependent developmental perturbations in physiological processes with possible long-term consequences for health status.

Author Contributions: Conceptualisation, A.S., A.V. and R.M.; Formal analysis, A.S., G.P., P.D.P., A.D.A., O.P., S.F., A.V. and R.M.; Funding acquisition, R.M.; Investigation, A.S., M.S., J.T., G.P., P.D.P., E.M., D.C. and M.M.; Project administration, A.S., O.P., A.V. and R.M.; Resources, A.D.A., C.V., R.P., A.V. and R.M.; Supervision, A.V. and R.M.; Visualization, A.S., M.S., G.P., P.D.P., E.M., D.C. and O.P.; Writing—original draft, A.S., A.V. and R.M.; Writing—review \& editing, J.T., G.P., P.D.P., A.D.A., C.V., O.P., S.F. and R.P. All authors have read and agreed to the published version of the manuscript.

Funding: Prin 2010-2011 and Università di Napoli Parthenope Ricerca locale 2017 to R.M.

Institutional Review Board Statement: The experimental protocol was approved by the Ethical Committees of the University of Salerno and by the Italian Ministry of Education, University and Research (authorisation number: 45/2014-PR 17 November 2014).

Informed Consent Statement: Not applicable.

Data Availability Statement: The data that support the findings of this study are available from the corresponding author upon reasonable request.

Conflicts of Interest: The authors declare no conflict of interest.

\section{References}

1. Rubin, B.S. Bisphenol A: An endocrine disruptor with widespread exposure and multiple effects. J. Steroid. Biochem. Mol. Biol. 2011, 127, 27-34. [CrossRef]

2. Corrales, J.; Kristofco, L.A.; Steele, W.B.; Yates, B.S.; Breed, C.S.; Williams, E.S.; Brooks, B.W. Global Assessment of Bisphenol A in the Environment: Review and Analysis of Its Occurrence and Bioaccumulation. Dose-Response Int. J. 2015, 13, 1-29. [CrossRef]

3. Chianese, R.; Troisi, J.; Richards, S.; Scafuro, M.; Fasano, S.; Guida, M.; Pierantoni, R.; Meccariello, R. Bisphenol A in reproduction: Epigenetic effects. Curr. Med. Chem. 2018, 25, 748-770. [CrossRef]

4. Murata, M.; Kang, J.H. Bisphenol A (BPA) and cell signaling pathways. Biotechnol. Adv. 2018, 36, 311-327. [CrossRef]

5. Santoro, A.; Chianese, R.; Troisi, J.; Richards, S.; Nori, S.; Fasano, S.; Guida, M.; Plunk, E.; Viggiano, A.; Pierantoni, R.; et al. Neuro-toxic and reproductiveeffects of BPA. Curr. Neuropharmacol. 2019, 17, 1109-1132. [CrossRef]

6. Tavares, R.S.; Escada-Rebelo, S.; Correia, M.; Mota, P.C.; Ramalho-Santos, J. The non-genomic effects of endocrine-disrupting chemicals on mammalian sperm. Reproduction 2016, 151, R1-R13. [CrossRef] [PubMed]

7. Peretz, J.; Vrooman, L.; Ricke, W.A.; Hunt, P.A.; Ehrlich, S.; Hauser, R.; Padmanabhan, V.; Taylor, H.S.; Swan, S.H.; VandeVoort, C.A.; et al. Bisphenol A and Reproductive Health: Update of Experimental and Human Evidence. Environ. Health Perspect. 2007, 8, 775-778.

8. Vandenberg, L.N.; Ehrlich, S.; Belcher, S.M.; BenJonathan, N.; Dolinoy, D.C.; Hugo, E.R.; Hunt, P.A.; Newbold, R.R.; Rubin, B.S.; Saili, K.S.; et al. Low dose effects of Bisphenol A: An integrated review of in vitro, laboratory animal and epidemiology studies. Endocr. Disrupt. 2013, 1, e2507. [CrossRef]

9. Le Magueresse-Battistoni, B.; Multigner, L.; Beausoleil, C.; Rousselle, C. Effects of bisphenol A on metabolism and evidences of a mode of action mediated through endocrine disruption. Mol. Cell. Endocrinol. 2018, 475, 74-91. [CrossRef]

10. D'Angelo, S.; Scafuro, M.; Meccariello, R. BPA and nutraceuticals, simultaneous effects on endocrine functions. Endocr. Metab. Immune. Disord. Drug Targets 2019, 19, 594-604. [CrossRef] 
11. Genuis, S.J.; Beesoon, S.; Birkholz, D.; Lobo, R.A. Human Excretion of Bisphenol A: Blood, Urine, and Sweat (BUS) Study. J. Environ. Public Health 2012, 2012, 185731. [CrossRef]

12. Nunez, A.A.; Kannan, K.; Giesy, J.P.; Fang, J.; Clemens, L.G. Effects of bisphenol A on energy balance and accumulation in brown adipose tissue in rats. Chemosphere 2001, 42, 917-922. [CrossRef]

13. Mercogliano, R.; Santonicola, S. Investigation on bisphenol A levels in human milk and dairy supply chain: A review. Food Chem. Toxicol. 2018, 114, 98-107. [CrossRef]

14. Dualde, P.; Pardo, O.; Corpas-Burgos, F.; Kuligowski, J.; Gormaz, M.; Vento, M.; Pastor, A.; Yusà, V. Biomonitoring of bisphenols A, F, S in human milk and probabilistic risk assessment for breastfed infants. Sci. Total Environ. 2019, 668, 797-805. [CrossRef]

15. Mørck, T.J.; Sorda, G.; Bechi, N.; Rasmussen, B.S.; Nielsen, J.B.; Ietta, F.; Rytting, E.; Mathiesen, L.; Paulesu, L.; Knudsen, L.E. Placental transport and in vitro effects of Bisphenol A. Reprod. Toxicol. 2010, 30, 131-137. [CrossRef]

16. Corbel, T.; Gayrard, V.; Puel, S.; Lacroix, M.Z.; Berrebi, A.; Gil, S.; Viguie, C.; Toutain, P.L.; Picard-Hagen, N. Bidirectional placental transfer of Bisphenol A and its main metabolite, Bisphenol A Glucuronide, in the isolated perfused human placenta. Reprod. Toxicol. 2014, 47, 51-58. [CrossRef] [PubMed]

17. Troisi, J.; Giugliano, L.; D’Antonio, A.; Viggiano, A.; Meccariello, R.; Scafuro, M.; Monda, M.; Colucci, A.; Scala, G.; Cofano, M.; et al. Placental Vascularization and Apoptosis in Rats Orally Exposed to Low Doses of Bisphenol A. Open J. Obstet. Gynecol. 2018, 8, 958-969. [CrossRef]

18. Roepke, T.A.; Yang, J.A.; Yasrebi, A.; Mamounis, K.J.; Oruc, E.; Zama, A.M.; Uzumcu, M. Regulation of arcuate genes by developmental exposures to endocrine-disrupting compounds in female rats. Reprod. Toxicol. 2016, 62, 18-26. [CrossRef]

19. Desai, M.; Ferrini, M.G.; Han, G.; Jellyman, J.K.; Ross, M.G. In vivo maternal and in vitro BPA exposure effects on hypothalamic neurogenesis and appetite regulators. Environ. Res. 2018, 164, 45-52. [CrossRef]

20. Di Pietro, P.; D’Auria, R.; Viggiano, A.; Ciaglia, E.; Meccariello, R.; Dello Russo, R.; Puca, A.A.; Vecchione, C.; Nori, S.L.; Santoro, A. Bisphenol A induces DNA damage in cells exerting immunosurveillance functions at peripheral and central level by differentially modulating estrogen receptors expression. Chemosphere 2020, 254, 126819. [CrossRef]

21. Eid, J.I.; Eissa, S.M.; El-Ghor, A.A. Bisphenol A induces oxidative stress and DNA damage in hepatic tissue of female rat offspring. JOBAZ 2015, 71, 10-19. [CrossRef]

22. Hugo, E.R.; Brandebourg, T.D.; Woo, J.G.; Loftus, J.; Alexander, J.W.; Ben-Jonathan, N. Bisphenol A at environmentally relevant doses inhibits adiponectin release from human adipose tissue explants and adipocytes. Environ. Health Perspect. 2008, 116, 1642-1647. [CrossRef] [PubMed]

23. Ben-Jonathan, N.; Hugo, E.R.; Brandebourg, T.D. Effects of bisphenol A on adipokine release from human adipose tissue: Implications for the metabolic syndrome. Mol. Cell. Endocrinol. 2009, 304, 49-54. [CrossRef]

24. Huc, L.; Lemarié, A.; Guéraud, F.; Héliès-Toussaint, C. Low concentrations of bisphenol A induce lipid accumulation mediated by the production of reactive oxygen species in the mitochondria of HepG2 cells. Toxicol. In Vitro 2012, 26, 709-717. [CrossRef] [PubMed]

25. Ke, Z.H.; Pan, J.X.; Jin, L.Y.; Xu, H.Y.; Yu, T.T.; Ullah, K.; Rahman, T.U.; Ren, J.; Cheng, Y.; Dong, X.Y.; et al. Bisphenol A Exposure May Induce Hepatic Lipid Accumulation via Reprogramming the DNA Methylation Patterns of Genes Involved in Lipid Metabolism. Sci. Rep. 2016, 6, 31331. [CrossRef] [PubMed]

26. Legeay, S.; Faure, S. Is bisphenol A an environmental obesogen? Fundam. Clin. Pharmacol. 2017, 6, 594-609. [CrossRef] [PubMed]

27. Chianese, R.; Viggiano, A.; Urbanek, K.; Cappetta, D.; Troisi, J.; Scafuro, M.; Guida, M.; Esposito, G.; Ciuffreda, L.P.; Rossi, F.; et al. Chronic exposure to low dose of bisphenol A impacts the first round of spermatogenesis via SIRT1 modulation. Sci. Rep. 2018, 8, 2961. [CrossRef]

28. Zhang, T.; Kraus, W.L. SIRT1-dependent Regulation of Chromatin and Transcription: Linking NAD ${ }^{+}$Metabolism and Signaling to the Control of Cellular Functions. Biochim. Biophys. Acta 2010, 1804, 1666-1675. [CrossRef]

29. D'Angelo, S.; Mele, E.; Di Filippo, F.; Viggiano, A.; Meccariello, R. Sirt1 activity in the brain: Simultaneous effects on energy homeostasis and reproduction. Int. J. Environ. Res. Public Health 2021, 18, 1243. [CrossRef]

30. Jing, H.; Lin, H. Sirtuins in Epigenetic Regulation. Chem. Rev. 2015, 115, 2350-2375. [CrossRef]

31. Elibol, B.; Kilic, U. High Levels of SIRT1 Expression as a Protective Mechanism Against Disease-Related Conditions. Front. Endocrinol. 2018, 9, 614. [CrossRef]

32. Scisciola, L.; Sarno, F.; Carafa, V.; Cosconati, S.; Di Maro, S.; Ciuffreda, L.; De Angelis, A.; Stiuso, P.; Feoli, A.; Sbardella, G.; et al. Two novel SIRT1 activators, SCIC2 and SCIC2.1, enhance SIRT1-mediated effects in stress response and senescence. Epigenetics 2020, 15, 664-683. [CrossRef] [PubMed]

33. Piegari, E.; Cozzolino, A.; Ciuffreda, L.P.; Cappetta, D.; De Angelis, A.; Urbanek, K.; Rossi, F.; Berrino, L. Cardioprotective effects of miR-34a silencing in a rat model of doxorubicin toxicity. Sci. Rep. 2020, 10, 12250. [CrossRef] [PubMed]

34. Piegari, E.; Russo, R.; Cappetta, D.; Esposito, G.; Urbanek, K.; Dell'Aversana, C.; Altucci, L.; Berrino, L.; Rossi, F.; De Angelis, A. MicroRNA-34a regulates doxorubicin-induced cardiotoxicity in rat. Oncotarget 2016, 7, 62312-62326. [CrossRef]

35. De Angelis, A.; Piegari, E.; Cappetta, D.; Russo, R.; Esposito, G.; Ciuffreda, L.P.; Ferraiolo, F.A.; Frati, C.; Fagnoni, F.; Berrino, L.; et al. SIRT1 activation rescues doxorubicin-induced loss of functional competence of human cardiac progenitor cells. Int. J. Cardiol. 2015, 189, 30-44. [CrossRef] [PubMed]

36. Li, X. SIRT1 and energy metabolism. Acta Biochim. Biophys. Sin. 2013, 45, 51-60. [CrossRef] [PubMed]

37. Ding, R.B.; Bao, J.; Deng, C.X. Emerging roles of SIRT1 in fatty liver diseases. Int. J. Biol. Sci. 2017, 13, 852-867. [CrossRef] 
38. Wang, Y.; Pang, W.J.; Wei, N.; Xiong, Y.; Wu, W.J.; Zhao, C.Z.; Shen, Q.W.; Yang, G.S. Identification, stability and expression of Sirt1 antisense long non-coding RNA. Gene 2014, 539, 117-124. [CrossRef] [PubMed]

39. Wang, G.Q.; Wang, Y.; Xiong, Y.; Chen, X.C.; Ma, M.L.; Cai, R.; Gao, Y.; Sun, Y.M.; Yang, G.S.; Pang, W.J. Sirt1 AS lncRNA interacts with its mRNA to inhibit muscle formation by attenuating function of miR-34a. Sci. Rep. 2016, 6, 21865. [CrossRef]

40. Liu, J.; Wu, W.; Jin, J. A novel mutation in SIRT1-AS leading to a decreased risk of HCC. Oncol. Rep. 2015, 34, 2343-2350. [CrossRef] [PubMed]

41. Calafat, A.M.; Ye, X.; Wong, L.Y.; Reidy, J.A.; Needham, L.L. Exposure of the U.S. population to bisphenol A and 4tertiaryoctylphenol: 2003-2004. Environ. Health Perspect. 2008, 116, 39-44. [CrossRef]

42. Trasande, L.; Attina, T.M.; Blustein, J. Association between urinary bisphenol A concentration and obesity prevalence in children and adolescents. JAMA 2012, 308, 1113-1121. [CrossRef]

43. Do, M.T.; Chang, V.C.; Mendez, M.A.; de Groh, M. Urinary bisphenol A and obesity in adults: Results from the Canadian Health Measures Survey. Health Promot. Chronic Dis. Prev. Can. 2017, 37, 403-412. [CrossRef]

44. Chevalier, N.; Fénichel, P. Bisphenol A: Targeting metabolic tissues. Rev. Endocr. Metab. Disord. 2015, 16, 299-309. [CrossRef] [PubMed]

45. Vandenberg, L.N.; Hunt, P.A.; Gore, A.C. Endocrine disruptors and the future of toxicology testing-lessons from CLARITY-BPA. Nat. Rev. Endocrinol. 2019, 15, 366-374. [CrossRef] [PubMed]

46. Commission Implementing Regulation (EU) No 321/2011 of 1 April 2011 Amending Regulation (EU) No 10/2011 as Regards the Restriction of Use of Bisphenol A in Plastic Infant Feeding Bottles Text with EEA Relevance. 2011. Available online: http:/ / data.europa.eu/eli/reg_impl/2011/321/oj (accessed on 8 August 2021).

47. Andra, S.S.; Charisiadis, P.; Arora, M.; van Vliet-Ostaptchouk, J.V.; Makris, K.C. Biomonitoring of human exposures to chlorinated derivatives and structural analogs of bisphenol A. Environ. Int. 2015, 85, 352-379. [CrossRef]

48. Ullah, A.; Pirzada, M.; Jahan, S.; Ullah, H.; Shaheen, G.; Rehman, H.; Siddiqui, M.F.; Butt, M.A. Bisphenol A and its analogs bisphenol B, bisphenol $\mathrm{F}$, and bisphenol S: Comparative in vitro and in vivo studies on the sperms and testicular tissues of rats. Chemosphere 2018, 209, 508-516. [CrossRef]

49. Rochester, J.R.; Bolden, A.L. Bisphenol S and F: A Systematic.Review and Comparison of the Hormonal Activity of Bisphenol A Substitutes. Environ. Health Perspect. 2015, 123, 643-650. [CrossRef] [PubMed]

50. EFSA Panel on Food Contact Materials, Enzymes, Flavourings and Processing Aids (CEF). Scientific Opinion on the risks to public health related to the presence of bisphenol A (BPA) in foodstuffs. EFSA J. 2015, 13, 3978. [CrossRef]

51. EFSA. A statement on the developmental immunotoxicity ofbisphenol A (BPA): Answer to the question from the Dutch Ministry of Health, Welfare and Sport. EFSA J. 2016, 14, 4580.

52. Nachman, R.M.; Hartle, J.C.; Lees, P.S.; Groopman, J.D. Early Life Metabolism of Bisphenol A: A Systematic Review of the Literature. Curr. Environ. Health Rep. 2014, 1, 90-100. [CrossRef]

53. Negri-Cesi, P. Bisphenol A Interaction with Brain Development and Functions. Dose Response 2015, 13, 1559325815590394 [CrossRef]

54. Tumani, H.; Huss, A.; Bachhuber, F. The cerebrospinal fluid and barriers-anatomic and physiologic considerations. Handb. Clin. Neurol. 2017, 146, 21-32. [PubMed]

55. Ghersi-Egea, J.F.; Strazielle, N.; Catala, M.; Silva-Vargas, V.; Doetsch, F.; Engelhardt, B. Molecular anatomy and functions of the choroidal blood-cerebrospinal fluid barrier in health and disease. Acta Neuropathol. 2018, 135, 337-361. [CrossRef]

56. Santoro, A.; Spinelli, C.C.; Martucciello, S.; Nori, S.L.; Capunzo, M.; Puca, A.A.; Ciaglia, E. Innate immunity and cellular senescence: The good and the bad in the developmental and aged brain. J. Leukoc. Biol. 2018, 103, 509-524. [CrossRef] [PubMed]

57. Scelsi, C.L.; Rahim, T.A.; Morris, J.A.; Kramer, G.J.; Gilbert, B.C.; Forseen, S.E. The Lateral Ventricles: A Detailed Review of Anatomy, Development, and Anatomic Variations. Am. J. Neuroradiol. 2020, 41, 566-572. [CrossRef]

58. Paquette, N.; Shi, J.; Wang, Y.; Lao, Y.; Ceschin, R.; Nelson, M.D.; Panigrahy, A.; Lepore, N. Ventricular shape and relative position abnormalities in preterm neonates. Neuroimage Clin. 2017, 15, 483-493. [CrossRef] [PubMed]

59. Wang, W.; Yan, C.; Zhang, J.; Lin, R.; Lin, Q.; Yang, L.; Ren, F.; Zhang, J.; Ji, M.; Li, Y. SIRT1 inhibits TNF- $\alpha$-induced apoptosis of vascular adventitial fibroblasts partly through the deacetylation of FoxO1. Apoptosis 2013, 18, 689-701. [CrossRef]

60. Tang, L.; Chen, Q.; Meng, Z.; Sun, L.; Zhu, L.; Liu, J.; Hu, J.; Ni, Z.; Wang, X. Suppression of Sirtuin-1 Increases IL-6 Expression by Activation of the Akt Pathway During Allergic Asthma. Cell Physiol. Biochem. 2017, 43, 1950-1960. [CrossRef]

61. Kauppinen, A.; Suuronen, T.; Ojala, J.; Kaarniranta, K.; Salminen, A. Antagonistic crosstalk between NF-kB and SIRT1 in the regulation of inflammation and metabolic disorders. Cell Signal. 2013, 25, 1939-1948. [CrossRef] [PubMed]

62. Khorkova, O.; Myers, A.J.; Hsiao, J.; Wahlestedt, C. Natural antisense transcripts. Hum. Mol. Genet. 2014, 23, R54-R63. [CrossRef]

63. Qian, W.; Cai, X.; Qian, Q. Sirt1 antisense long non-coding RNA attenuates pulmonary fibrosis through sirt1-mediated epithelialmesenchymal transition. Aging 2020, 12, 4322-4336. [CrossRef] [PubMed]

64. Mokhberian, N.; Hashemi, S.M.; Jajarmi, V.; Eftekhary, M.; Koochaki, A.; Ghanbarian, H. Sirt1 antisense transcript is downregulated in human tumors. Mol. Biol. Rep. 2019, 46, 2299-2305. [CrossRef]

65. Ma, Y.; Xia, W.; Wang, D.Q.; Wan, Y.J.; Xu, B.; Chen, X.; Li, Y.Y.; Xu, S.Q. Hepatic DNA methylation modifications in early development of rats resulting from perinatal BPA exposure contribute to insulin resistance in adulthood. Diabetologia 2013, 56, 2059-2067. [CrossRef] 
66. Li, Q.; Zhang, H.; Zou, J.; Mai, H.; Su, D.; Feng, X.; Feng, D. Bisphenol A exposure induces cholesterol synthesis and hepatic steatosis in C57BL/6 mice by down-regulating the DNA methylation levels of SREBP-2. Food Chem. Toxicol. 2019, 133, 110786. [CrossRef] [PubMed]

67. Yang, H.; Yan, B.; Liao, D.; Huang, S.; Qiu, Y. Acetylation of HDAC1 and degradation of SIRT1 form a positive feedback loop to regulate p53 acetylation during heat-shock stress. Cell Death. Dis. 2015, 6, e1747. [CrossRef] [PubMed]

68. Erion, D.M.; Yonemitsu, S.; Nie, Y.; Nagai, Y.; Gillum, M.P.; Hsiao, J.J.; Iwasaki, T.; Stark, R.; Weismann, D.; Yu, X.X.; et al. SirT1 knockdown in liver decreases basal hepatic glucose production and increases hepatic insulin responsiveness in diabetic rats. Proc. Natl. Acad. Sci. USA 2009, 106, 11288-11293. [CrossRef]

69. Li, X.; Zhang, S.; Blander, G.; Tse, J.G.; Krieger, M.; Guarente, L. SIRT1 deacetylates and positively regulates the nuclear receptor LXR. Mol. Cell 2007, 28, 91-106. [CrossRef]

70. Errico, S.; Portaccio, M.; Nicolucci, C.; Meccariello, R.; Chianese, R.; Scafuro, M.; Lepore, M.; Diano, N. Complementary experimental approaches for liver analysis in BPA exposed rats. J. Pharm. Biomed. Anal. 2019, 165, 207-212. [CrossRef]

71. Kosarac, I.; Kubwabo, C.; Lalonde, K.; Foster, W. A novel method for the quantitative determination of free and conjugated bisphenol A in human maternal and umbilical cord blood serum using a two-step solid phase extraction and gas chromatography/tandem mass spectrometry. J. Chromatog. B 2012, 898, 90-94. [CrossRef]

72. Guida, M.; Troisi, J.; Ciccone, C.; Granozio, G.; Cosimato, C.; Sardo, A.D.S.; Ferrara, C.; Guida, M.; Nappi, C.; Zullo, F. Bisphenol A and congenital developmental defects in humans. Mutat. Res. /Fundam. Mol. Mech. Mutagenesis 2015, 774, 33-39. [CrossRef]

73. Landolfi, A.; Troisi, J.; Savanelli, M.C.; Vitale, C.; Barone, P.; Amboni, M. Bisphenol A glucuronidation in patients with Parkinson's disease. Neurotoxicology 2017, 63, 90-96. [CrossRef]

74. Paxinos, G.; Watson, C. The Rat Brain in Stereotaxic Coordinates, 6th ed.; Academic Press: San Diego, CA, USA, 2007.

75. Annunziata, C.; Lama, A.; Pirozzi, C.; Cavaliere, G.; Trinchese, G.; Di Guida, F.; Nitrato Izzo, A.; Cimmino, F.; Paciello, O.; De Biase, D.; et al. Palmitoylethanolamide counteracts hepatic metabolic inflexibility modulating mitochondrial function and efficiency in diet-induced obese mice. FASEB J. 2020, 34, 350-364. [CrossRef] [PubMed]

76. Liang, W.; Menke, A.L.; Driessen, A.; Koek, G.H.; Lindeman, J.H.; Stoop, R.; Havekes, L.M.; Kleemann, R.; van den Hoek, A.M. Establishment of a General NAFLD Scoring System for Rodent Models and Comparison to Human Liver Pathology. PLoS ONE 2014, 9, e115922. [CrossRef] [PubMed]

77. Lowry, O.H.; Rosenbrough, N.J.; Farr, A.L.; Randall, R.J. Protein measurement with the Folin phenol reagent. J. Biol. Chem. 1951, 193, 265-275. [CrossRef]

78. Livak, K.J.; Schmittgen, T.D. Analysis of relative gene expression data using real-time quantitative PCR and the 2(-Delta Delta C(T)) Method. Methods 2001, 25, 402-408. [CrossRef] 